\title{
A Review on the Etiology, Prevention, and Management of Ureteral Injuries During Obstetric and Gynecologic Surgeries
}

\author{
Idowu Pius Ade-Ojo (D) \\ Olatoyosi Tijani \\ 'Department of Obstetrics Gynecology, \\ Ekiti State University, Ado-Ekiti, Nigeria; \\ ${ }^{2}$ Department of Obstetrics and \\ Gynecology, Ekiti State University \\ Hospital, Ado-Ekiti, Nigeria
}

\begin{abstract}
Iatrogenic ureteral injuries are a rare but serious complication of some gynecological and obstetric procedures with both high morbidity and legal implications. The incidence varies widely depending on the type and extent of the surgeries with about $70 \%$ unrecognized intraoperatively. When recognized intraoperatively and promptly managed, the prognosis is good. Ureteral injuries recognized postoperatively come with dire consequences for the patients and are litigation prone. Due to the proximity of the lower half of the ureters to the pelvic organs, $50 \%$ of the cases of injuries to the ureter occur within the jurisdiction of gynecological and obstetric practice. A good knowledge of the etiology, predisposing factors, appropriate surgical skills, proper identification of the course and deviation of the ureters, and intraoperative recognition of inadvertent damage to the ureter and its vasculature is required by all obstetricians and gynecologists to reduce the incidence of ureteral injuries by at least $50 \%$. This review aims to add to what is already known, particularly among obstetricians and gynecologists practicing in resource-constrained settings.
\end{abstract}

Keywords: ureteral injuries, obstetrics and gynecology

\section{Introduction}

Ureteral injuries, defined as any recognized or unrecognized iatrogenic trauma to the ureter that prevents it from functioning properly or effectively, are rare but constitute one of the most serious complications of gynecological and obstetric surgeries. ${ }^{1,2}$ The concern for ureteral injuries, mostly by gynecologists, is justified because it accounts for $17 \%$ of non-obstetric legal action instituted against gynecologists in the USA. ${ }^{3}$ Ureteral injuries occur in about $0.2-1 \%$ of all pelvic surgeries and $30 \%$ of radical hysterectomies. ${ }^{3,4}$ Obstetric and gynecological surgeries, however, account for about $50 \%$ of all these injuries. ${ }^{1-5}$ They are quite rare during cesarean deliveries, but cesarean hysterectomies increase the incidence to $3 \%$, which is a 7 -fold increase in injuries compared to non-obstetric hysterectomies. ${ }^{6,7}$ The simple fact that $50 \%$ of ureteral injuries occur with obstetric and gynecological procedures means that there should be in-depth knowledge of the subject of ureteral injuries among physicians in this specialty. Even in the hands of excellent surgeons, because of the course, relations, and the ability of the pathologies of some pelvic organs to revolve around or displace the ureter, the ureter, may be inadvertently damaged during pelvic surgeries. This review will add to what is already known on this subject and this may help to reduce the incidence of ureteral injuries contributed by the practice of obstetrics and gynecology.
Correspondence: Idowu Pius Ade-Ojo Department of Obstetrics Gynecology, Ekiti State University, Ado-Ekiti, Nigeria Tel +2348033886I73

Email ipadeojo@eksu.edu.ng 


\section{Methods}

We searched PubMed for both indexed and non-indexed human-related studies before July 31st, 2021 for this review. The following MeSH terms were used for the search; "ureter", "wound and injury", "causality", "prevention and control", "obstetrics", "gynecological surgical procedure". These terms were combined using "AND" to generate a subset of citations relevant for our review. Studies that vividly discussed the etiology, preventive strategies, intraoperative recognition, investigations, and management of ureteric injuries during obstetrics and gynecological surgeries were included. We also included other articles not captured on the PubMed search but were frequently cited on Web of Science and google scholars. Articles excluded were those not written in the English language. Our searches yielded a total of 257 articles, which were screened to 45 as showing in the flow chart below and formed the basis of this review (Figure 1).

\section{Etiology}

The possible causes of iatrogenic ureteric injuries include gynecologic procedures like abdominal hysterectomy, vaginal hysterectomy, anterior colporrhaphy, laparoscopic hysterectomy; ${ }^{8}$ obstetric causes and predisposing factors like cesarean hysterectomy, fetal macrosomia, cephalopelvic disproportion, placenta previa, and morbidly adherent placentas involving the pelvic sidewalls, difficult neonatal

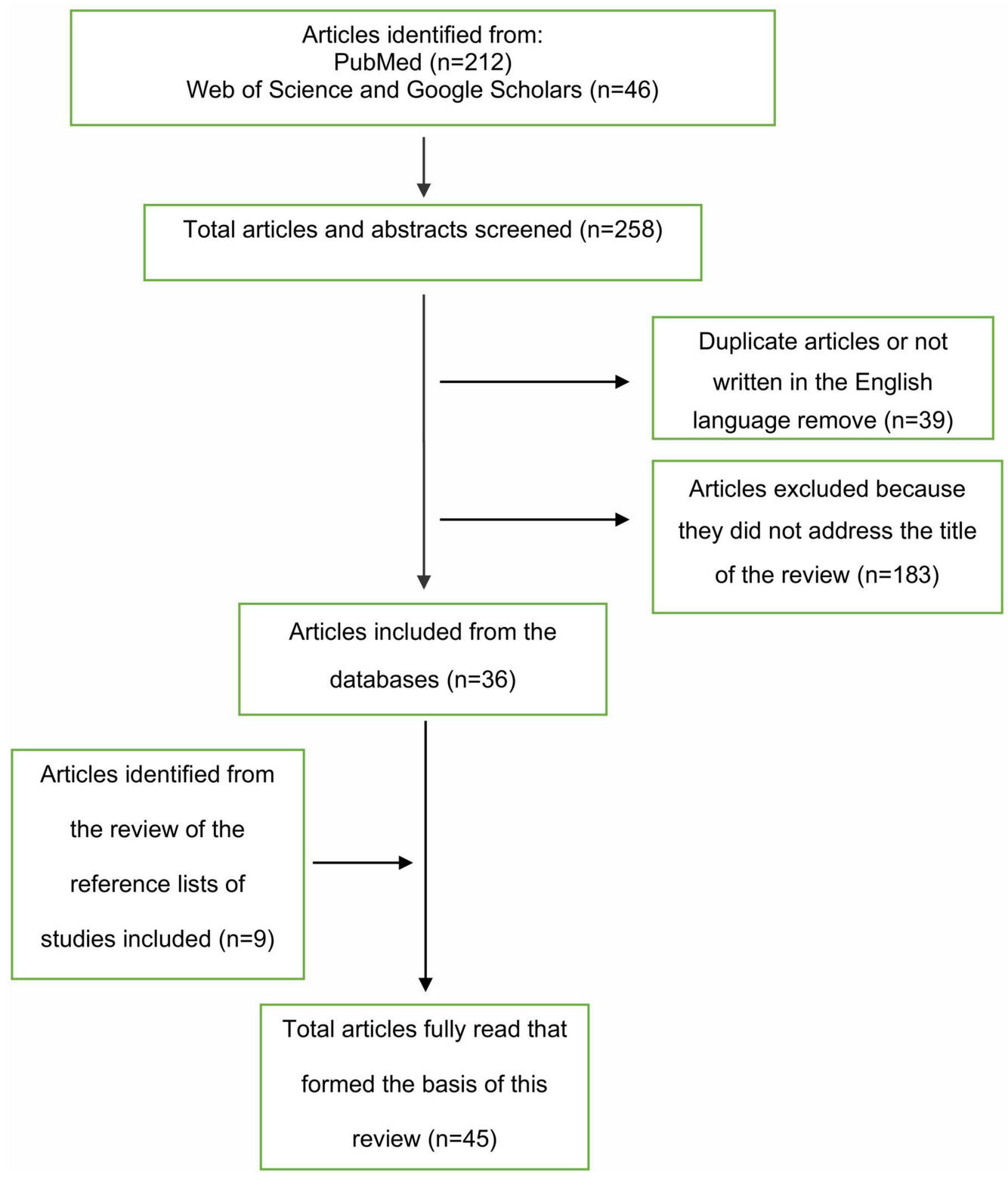

Figure I Showing the flowchart of the literature review. 
extraction, prolonged labor, and abnormal fetal lie. ${ }^{9,10}$ Other risk factors for iatrogenic injury include causes of pelvic adhesion like the previous surgeries, ${ }^{11}$ endometriosis, and prior radiation therapy, advanced abdominopelvic cancers, ${ }^{12-14}$ enlarged uterus at hysterectomy, cervical fibroids, and broad ligament fibroids, limited experience of the surgeon, bleeding, and excessive use of diathermy, ${ }^{3}$ and transvaginal retrieval of oocytes (TOVR). ${ }^{15}$

\section{Types and Classification}

The types of ureteric injuries include crushing injury, ligation, transection, angulation, excision, ischemia from stripping, electrocoagulation, resection, and a combination of the above. ${ }^{16,17}$ These injuries are classified into 5 grades as described by Moore et al. ${ }^{17}$

Grade I - Hematoma (contusion or hematoma without devascularization)

Grade II - Laceration ( $<50 \%$ transection)

Grade III - Laceration ( $\geq 50 \%$ transection)

Grade IV - Laceration (complete transection with $<2 \mathrm{~cm}$ )

Grade V - Laceration (avulsion with $>2 \mathrm{~cm}$ of devascularization)

Advance one grade if multiple lesions exist.

\section{Prevention}

Preventive strategies for ureteric injuries can be general and specific. The general preventive strategies include preoperative radiological assessments like ultrasound scanning, intravenous pyelography (IVP), computerized tomography (CT) scanning, and magnetic resonance imaging (MRI) in selected patients to estimate the size of the masses to be excised and to delineate the path of the ureters. $^{18-21}$

Also, the passage of the urethral catheter is able to monitor urine output in the intra-operative and postoperative periods and also able to identify hematuria or anuria as possible indicators of ureteric injury. ${ }^{22}$

During the intraoperative period, general preventive measures include generous surgical exposure to limit the risk of inadvertent ureteric injury, use of appropriate incision to ensure adequate access, and reduce the need for manipulation of the pelvic organs at the surgery. ${ }^{18,20,22}$ It is very important to avoid blind clamping and ligation when bleeding occurs and identifying the ureters within the operation field to avoid iatrogenic damage. Adequate mobilization of the bladder away from the surgical field with a retractor will also remove the lower segments of the ureters away from inadvertent injuries. ${ }^{22,23}$

The specific prevention of injuries includes ligation and suturing of cardinal ligaments as close to the uterus as possible and mobilization of the ureters laterally and the bladder caudally during abdominal uterine surgeries. ${ }^{22,23}$ During vaginal approaches, uterine vessels should be ligated as close to the uterus as possible. Proper exposure of the vesical and uterine areas is very necessary as well as pulling off the cervix towards the lower end, to avoid injury to the ureter. While performing anterior colporrhaphy, dissection on lateral angle should be avoided as should the placement of deep sutures during the plication of the bladder. ${ }^{18,23}$ During laparoscopic surgery, mobilization of the fallopian tubes far from the pelvic sidewalls before electrocoagulation. ${ }^{20,21}$

In obstetric procedures, a high index of suspicion is necessary to prevent ureteral injuries. When peripartum hysterectomy becomes inevitable, sound operative techniques and direct visualization of the ureters as well as prophylactic stenting to reduce morbidity during peripartum hysterectomy for placenta accreta are some of the preventive measures. ${ }^{24}$ Gentle atraumatic fetal delivery to prevent lateralization of uterine incision when the head of the fetus is deeply impacted during cesarean section in the second stage of labor, careful repair of lateralization to the broad ligament and vagina, identification of the ureter after repair, and evaluation for patency are cardinal to preventing ureteric injuries. Preference for partial or subtotal to total cesarean hysterectomies by less experienced obstetricians is a wise decision during the learning curve. ${ }^{25}$

\section{Common Sites of Ureteral Injuries During Obstetrics and Gynecological Surgeries}

Figure 2 Approximately half of the entire length of the ureter crosses into the pelvis in a course fraught with hazard. ${ }^{26,27} \mathrm{In}$ the female genital tract, some pathologies can distort, encroach or encase the ureter, making it susceptible to iatrogenic injury during gynecological, obstetrics, and pelvic surgeries. ${ }^{26,27}$ The common sites of ureteric injury include the level of the infundibulopelvic ligament where the ureters run parallel to the ovarian vessels and the ureter forms the posterior boundary of the ovarian fossa. ${ }^{26,27}$ In this position, the ureters may be compromised by pelvic adhesions, endometriosis, ovarian tumors, and malignancies. Surgeons performing adnexectomies and laparoscopies should bear this in 


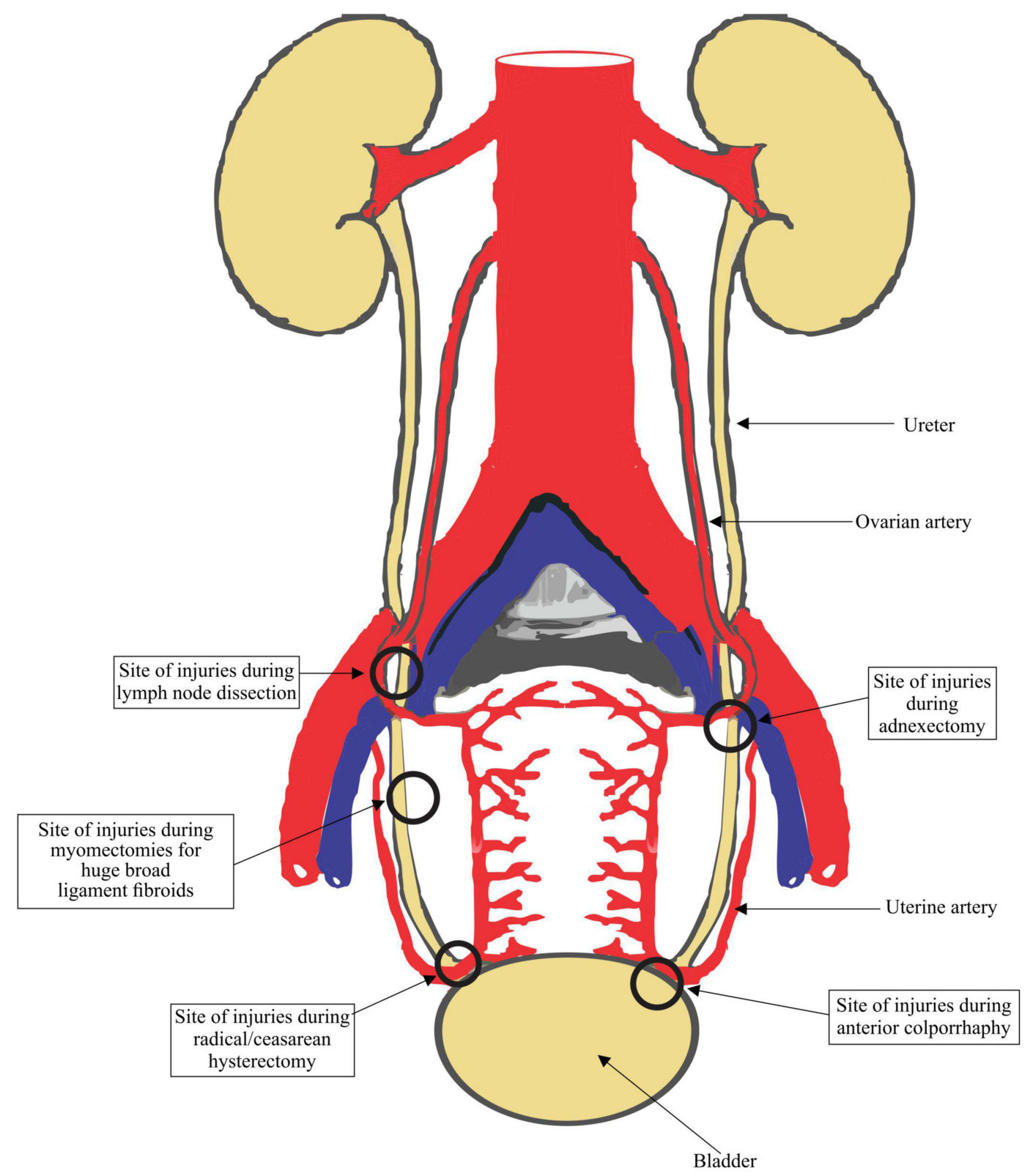

Figure 2 Showing the common sites of ureteral injuries.

mind to maintain good traction, avoid uncoordinated dissection, and excessive electrocoagulation to avoid transection or thermal injury to the ureter. ${ }^{21,26,28}$ At the ischial spine, the ureter lies lateral to the peritoneum of the uterosacral ligament and at the level of the internal os, about $1.5 \mathrm{~cm}$ lateral to the cervix, the uterine artery crosses the ureter from above. Large broad ligament fibroid and cervical fibroid can encroach on the ureter. ${ }^{26,27}$ This is the point that the ureter is susceptible to injury during abdominal, vaginal, and laparoscopic hysterectomies. Over the anterior vaginal fornix, the ureter turns anteriorly and medially to enter the bladder, within the ureteric tunnel of the cardiac ligament (tunnel of Wertheim) and the intravesical part, where it traverses the musculature of the bladder. ${ }^{29}$ At this point, morbidly adherent placenta and repair of lateralization of uterine incision can make the ureter vulnerable to injuries.

\section{Intraoperative Diagnosis}

Prompt diagnosis and appropriate treatment of identified cases should also be done to prevent the possible complications that may arise from the injuries. Prognosis is better when the diagnosis is made intraoperatively. It is, however, sad to note that approximately $70 \%$ of iatrogenic ureteric injuries are diagnosed postoperatively. ${ }^{18,20,21}$ Intraoperative 
identification enables prompt repair and decreased morbidity with fewer legal risks. ${ }^{28,30}$ In obstetric surgeries, diagnosis of intraoperative ureteric injuries could be difficult due to the reduced ureteral peristalsis in the third trimester as well as from the hypoperfusion and reduced urinary flow from hypotension and ongoing blood loss. A high degree of suspicion and specific vigilance is needed to decrease the incidence of missed injuries. Intraoperatively, it is important to first ensure adequate exposure of the sites where ureters are susceptible to injuries by packing bowel out of the way, controlling bleeding, and ensuring the theatre lights are appropriately positioned. Ureteral integrity should be checked by isolation and visual inspection of the ureters for contusion, suture ligation, wall discoloration, and lack of capillary refill. Furthermore, where a ureteric injury is suspected intraoperatively, the use of dyes to reveal the site of damage has been advocated. Indigo carmine, methylene blue, sodium fluorescein, phenazopyridine and riboflavin of vitamin B-complex are among the dyes that have been used. $^{31}$ Indigo carmine was commonly used before 2014 when the United States Department of Food and Drug Administration announced its worldwide shortage. ${ }^{31,32}$ Sodium fluorescein has been suggested as a good alternative. ${ }^{33,34}$ It results in very bright yellow tinge urine, which can be highly reflective and easier to detect when compared with methylene blue and phenazopyridine. ${ }^{34}$ It has also been found to be associated with a more favorable surgeons' satisfaction with fewer side effects. ${ }^{33,34}$ Resistance to cystoscopic passage of a retrograde ureteral catheterization would suggest ureteral obstruction (most definitive diagnostic method). Failure of advancement of the catheter indicates kinking, ligation, or crush injury, while the appearance of the catheter in the abdominal cavity indicates transection, whether partial or complete.

On table retrograde pyelography, a common definitive diagnostic method is done via an incision made in the bladder or via a cystoscope. It is a very accurate method of establishing the presence or absence of ureteric injury. It also allows simultaneous placement of the ureteric stent in the injured ureter. It also enables both ureters to be easily examined to rule out bilateral injuries. 1,14,36

\section{Clinical Presentation}

The clinical presentation of missed ureteral injury is usually apparent in the first few days following surgery, but it may be delayed by weeks, months, or years depending on the nature of the intraoperative injury. It includes ileus (due to urine within the peritoneal cavity), prolonged post-operative fever or overt urinary sepsis, persistent drainage of fluid from drains, the abdominal wound, or the vagina. Flank pain and costovertebral angle tenderness are common if the ureter has been ligated. An abdominal mass may be felt, representing a urinoma. A continuous leak of urine suggests a ureterovaginal fistula. Hematuria, gross or microscopic, oliguria, elevated serum creatinine levels, persistent abdominal distention, peritonitis, and secondary hypertension have been reported. ${ }^{21,37,38}$

\section{Postoperative Diagnosis}

Radio diagnostic investigations that could aid the diagnosis of ureteric injuries include intravenous pyelography (IVP), abdominal and pelvic computerized tomography scanning with intravenous contrast, magnetic resonance imaging, retrograde and antegrade pyelography, renal ultrasound scanning, cystoscopy, and dye tests. ${ }^{1,39}$

\section{Management}

Management is based on the timing of diagnosis, the etiology, the length and location of the injury, the patient's overall status, and other associated injuries. It ranges from an excellent reconstruction to a more conservative approach (in unstable patients). The precise nature of the injury should be defined to decide the best method of repair. The general principles of repair include minimal tension on anastomotic sites, preservation of blood supply, adequate debridement, adequate drainage, water-tight spatulated anastomosis, and use of only healthy ureters for reanastomosis. Preservation of the adventitial sheath and its blood supply with tension-free anastomosis by ureteric mobilization and minimal use of fine absorbable sutures to attain watertight closure should be ensured. Use of peritoneum or omentum to surround the anastomosis (omental wrap) may also be done. ${ }^{1,40}$ An abdominal drain that could be removed in 3-5 days should be placed and the bladder catheterized for continuous drainage for about a week. ${ }^{1,2}$ The stent may be removed in 3-6 weeks under cystoscopy as an office procedure and an intravenous pyelography (IVP) should be done to confirm ureteral integrity afterward. ${ }^{1,40}$

The options depend on whether the injury is recognized immediately, the level and type of the injury, and the presence of morbidities.

\section{Intraoperative Diagnosis and Management} Most gynecological and obstetric-induced ureteral injuries are located in the distal half of the ureters. If a ureter is 
included in the ligature and recognized intraoperatively, the ligature should be removed immediately, the integrity of the affected and non-affected ureters should be checked to rule out other associated injuries. The ureteral stent should be inserted and left in-situ of the affected ureter for 3-6 weeks. Intravenous pyelography should be done after the removal of the stent to confirm ureteral patency and exclude stricture. ${ }^{1,3}$

In a case of an inadvertent laceration and the transection less than $50 \%$ of the diameter of the ureter, an end-toend anastomosis of the healthy portions of the damaged ureter is preferable to avoid post-operative persistent ureteral leak or stenosis. ${ }^{1,14,19}$ This is followed by a ureteral stenting for 3-6 weeks and followed by an IVP as stated above.

If the transection involves greater than $50 \%$ or almost the entire width of the ureter, and the defect between the ends of the ureter is of a length where a tension-free anastomosis is possible, the surgical option involves direct ureter to ureter anastomosis (primary uretero-ureterostomy). ${ }^{1,14,16}$ This approach is also useful in ureteral contusion as a result of clamping by forceps. In this regard, the clamped segment is resected, and a primary uretero-ureterostomy is done ensuring a tension-free anastomosis. Caution must be exercised, however, as minor-appearing ureteral contusions may stricture later or break down secondary to unappreciated microvascular damage to the ureter. When in doubt, the injured portion of the ureter should be debrided before ureteroureterostomy. A ureteral stent should be left in-situ for 3-6 weeks and followed with an intravenous pyelography.

Another option for the management of ureteral injuries is re-implantation of the ureter into the bladder (ureteroneocystostomy). Ureteroneocystostomy is used to repair injured distal ureter that occurs so close to the bladder that the bladder does not need to be brought up to the ureteral stump with a psoas hitch or Boari procedure. ${ }^{1,14,16}$ Ureteroneocystostomy involves the creation of a submucosal tunnel for a nonrefluxing ureteral repair or a refluxing non-tunneled anastomosis that can be considered if the ureteral length is insufficient for tunneling. The distal portion is ligated using permanent or delayed absorbable suture, making it into a blind-ended tube. The repair should be stented postoperatively.

However, Vesico-Psoas hitch (mobilization of the bladder upwards to meet the proximal ureter and then affixing it to the psoas muscle) may be preferable to have a tension-free ureteroneocystostomy and because the distal third of the ureter has a tenuous independent blood supply. The procedure has a high (near 95\%) success rate. ${ }^{40}$
Injuries to the lower two-thirds of the ureter with long ureteral defects (too long to be bridged by bringing the bladder up in the psoas hitch procedure) can be managed with a Boari flap. ${ }^{1,41}$ A pedicle of the bladder is swung cephalad and tubularized to bridge the gap to the injured ureter. Abdominal drain for continuous abdominal drainage is done for $3-5$ days, the stent is removed after 6 weeks and an IVP is done in 3-6 months after to ensure patency and to rule out stricture. ${ }^{35,40}$

\section{Options for Delayed Recognition}

In cases of intraoperative missed diagnosis and delayed recognition, some urologists suggest stent placement as the first line of therapy for ureteral injuries with delayed recognition, ${ }^{1}$ while others recommend that these injuries be repaired openly as soon as possible. ${ }^{14,16,28}$ These authors cite low complication rates, which can be as low as in the repair of injuries that are recognized immediately. ${ }^{1,28}$ However, delayed diagnosis of the ureteral injury itself increases the complication rate of the repair significantly from $10 \%$ to $40 \%$ in one series, ${ }^{42,43}$ and some have advocated late repair up to 6 weeks to allow maximal resolution of perioperative inflammation. $1,28,44$ Usually, failure to place a stent is due to complete obstruction of the ureter or to a gap too long to bridge. ${ }^{1,44}$ If stent placement is achieved, open repair is required only in those patients with persistent leakage or ureteral stricture. ${ }^{1,16,44}$ The options of open repair depend on the length of the ureteral stricture and associated complications like fistulas, abscess formation, and the presence of urinomas (Figure 3). ${ }^{1,28,45}$

\section{Conclusion}

The lower half of the ureters enter the pelvis and run in a course too close to the organs of interest to the obstetricians and gynecologists in the female. These organs at times encroach on, encase or displace the ureters, making them vulnerable to injuries during gynecological and obstetrics procedures. Injury to an innocent ureter can make a surgeon presumed to have violated the principle of "first, do no harm" ("primum non nocere" or "non-maleficence"). Therefore, pelvic surgeons, obstetricians, and gynecologists must thread with caution to avoid medicolegal pitfalls that may follow ureteral injuries during gynecological and obstetrics procedures.

\section{Acknowledgments}

We acknowledge the expert contribution of Dr. Oluseyi Omotola Banjo a urologist in the Department of Surgery at the Federal Teaching Hospital and Afe Babalola 

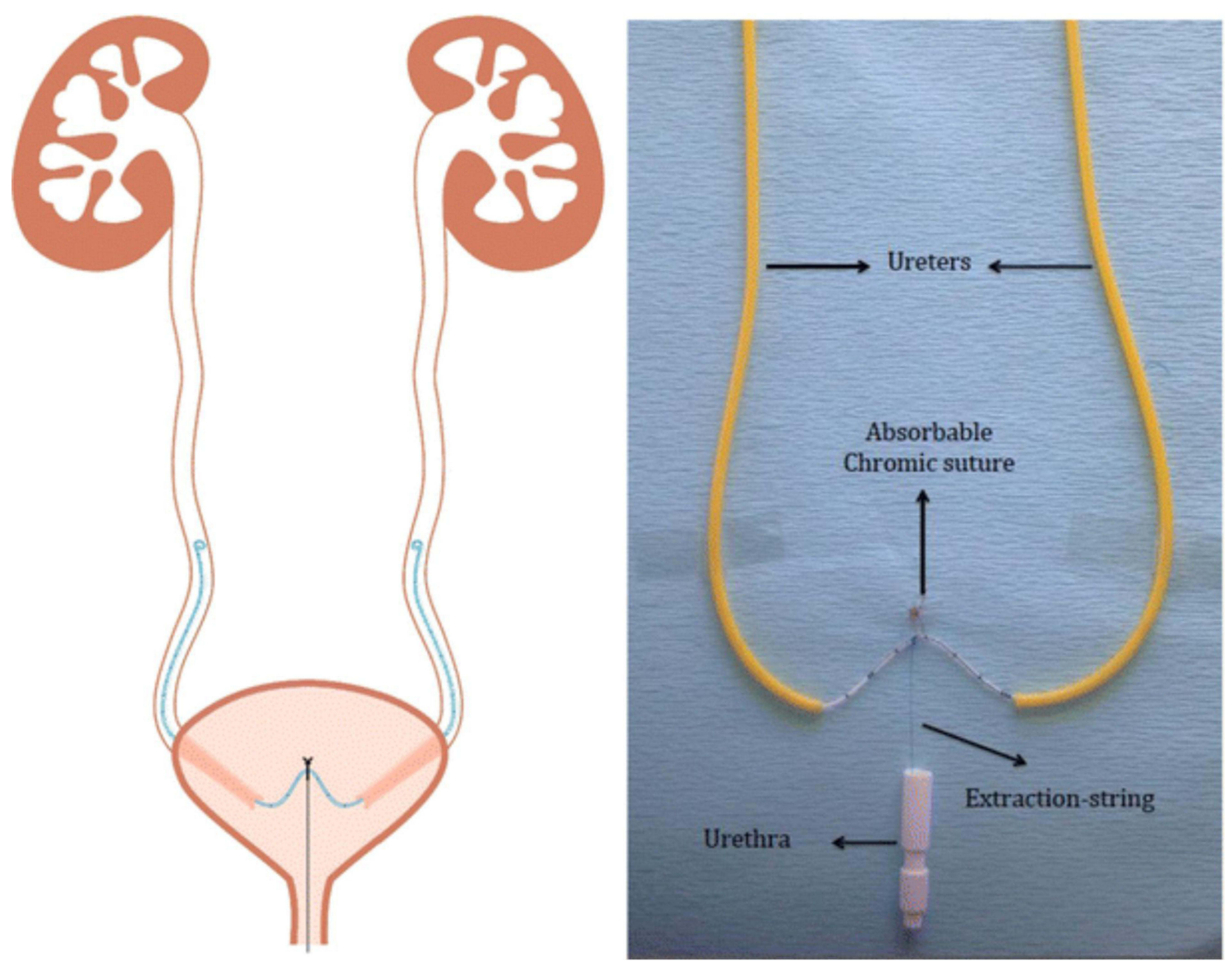

Figure 3 Showing double J ureteral stent.

Note: Reprinted by permission from Springer Nature Customer Service Centre GmbH: Springer Nature, International Urology and Nephrology, Nabavizadeh B, Keihani S, Hosseini Sharifi SH, Kajbafzadeh A-M. Insertion of a single double-J stent for bilateral open ureteral reimplantation: introducing a novel technique and assessment of feasibility. Int Urol Nephrol. 48(7): 1015-1019. doi:10.1007/s II255-016-1279-y, copyright 2016. ${ }^{45}$

University in Ekiti State, Nigeria, for his valuable contribution to the writeup on the 'management' section of the manuscript.

\section{Disclosure}

The authors report no conflicts of interest in this work.

\section{References}

1. Burks FN, Santucci RA. Management of iatrogenic ureteral injury. Ther Adv Urol. 2014;6(3):115-124. doi:10.1177/1756287214526767

2. Vasavada SP. Ureteral injury during gynecologic surgery - overview; November 12, 2020. Available from: https://emedicine.medscape.com article/454617-overview\#a5. Accessed August 23, 2021.

3. Jha S, Coomarasamy A, Chan KK. Ureteric injury in obstetric and gynecological surgery. Obstet Gynecol. 2004;6(4):203-208. doi:10.1576/toag.6.4.203.27016

4. Kumari Rani A. Urological injury in obstetric and gynecological surgery: a retrospective analysis of five years. IJOG. 2020;8 (2):18-22. doi:10.21088/ijog.2321.1636.8220.2

5. Jacob GP, Vilos GA, Al Turki F, et al. Ureteric injury during gynecological surgery - lessons from 20 cases in Canada. Facts Views Vis Obgyn. 2020;12(1):31-42.
6. Chalya PL, Massinde AN, Kihunrwa A, Simbila S. Iatrogenic ureteric injuries following abdominopelvic operations: a 10-year tertiary care hospital experience in Tanzania. World J Emerg Surg. 2015;10 (1):17. doi:10.1186/s13017-015-0011-z

7. Lo T-S, Wijaya T, Lo L-M, et al. Clinical relevance, and treatment selection of ureteral injury after cesarean section. Female Pelvic Med Reconstr Surg. 2016;22(5):303-306. doi:10.1097/SPV.000000000 0000275

8. Mamik MM, Antosh D, White DE, et al. Risk factors for lower urinary tract injury at the time of hysterectomy for benign reasons. Int Urogynecol J. 2014;25(8):1031-1036. doi:10.1007/s00192-0132308-3

9. Nawaz FH, Khan ZE, Rizvi J. Urinary tract injuries during obstetrics and gynaecological surgical procedures at the Aga Khan University Hospital Karachi, Pakistan: a 20-year review. Urol Int. 2007;78 (2):106-111. doi:10.1159/000098065

10. Visconti F, Quaresima P, Rania E, et al. Difficult cesarean section: a literature review. Eur $J$ Obstet Gynecol Reprod Biol. 2020;246:72-78. doi:10.1016/j.ejogrb.2019.12.026

11. Silver RM, Landon MB, Rouse DJ, et al. Maternal morbidity associated with multiple repeat cesarean deliveries. Obstet Gynecol. 2006;107(6):1226-1232. doi:10.1097/01.AOG.00002197 50.79480 .84

12. Smith IA, Cooper M. Management of ureteric endometriosis associated with hydronephrosis: an Australian case series of 13 patients. BMC Res Notes. 2010;3(1):45. doi:10.1186/1756-0500-3-45 
13. Keckstein J, Becker CM, Canis M, et al.; Working group of ESGE, ESHRE, and WES. Recommendations for the surgical treatment of endometriosis. Part 2: deep endometriosis. Hum Reprod Open. 2020;2020(1):hoaa002. doi:10.1093/hropen/hoaa002

14. Tohamy AZ, Samy HA, Salah T, Hussien MT, Hussein M. Ureteric injuries during cancer surgery presentation and management over a 20-year. Int Surg J. 2021;8(2):593. doi:10.18203/2349-2902. isj 20210370

15. Choudhary RA, Bhise NM, Mehendale AV, Ganla KN. Ureteric injury during transvaginal oocyte retrieval (TVOR) and review of literature. J Hum Reprod Sci. 2017;10(1):61-64. doi:10.4103/jhrs. JHRS_124_16

16. Delacroix SE, Winters JC. Urinary tract injures: recognition and management. Clin Colon Rectal Surg. 2010;23(2):104-112. doi:10.1055/s-0030-1254297

17. Moore EE, Cogbill TH, Jurkovich GJ, et al. Organ injury scaling III: chest wall, abdominal vascular, ureter, bladder, and urethra. J Trauma. 1992;33(3):337-339. doi:10.1097/00005373-199209000-00001

18. Chan JK, Morrow J, Manetta A. Prevention of ureteral injuries in gynecologic surgery. Am J Obstet Gynecol. 2003;188(5):1273-1277. doi:10.1067/mob.2003.269

19. Sharp HT, Adelman MR. Prevention, recognition, and management of urologic injuries during gynecologic surgery. Obstet Gynecol. 2016;127(6):1085-1096. doi:10.1097/AOG.0000000000001425

20. Findley AD, Solnik MJ. Prevention and management of urologic injury during gynecologic laparoscopy. Curr Opin Obstet Gynecol. 2016;28(4):323-328. doi:10.1097/GCO.0000000000000296

21. Janssen PF, Brölmann HAM, Huirne JAF. Causes and prevention of laparoscopic ureter injuries: an analysis of 31 cases during laparoscopic hysterectomy in the Netherlands. Surg Endosc. 2013;27 (3):946-956. doi:10.1007/s00464-012-2539-2

22. Cirstoiu M, Munteanu O. Strategies of preventing ureteral iatrogenic injuries in obstetrics-gynecology. $J$ Med Life. 2012;5(3):277-279.

23. Porges RF. Anterior colporrhaphy. GLOWM. 2009. doi:10.3843/ GLOWM.10044

24. Kwee A, Bots ML, Visser GHA, Bruinse HW. Emergency peripartum hysterectomy: a Prospective Study in the Netherlands. Eur J Obstet Gynecol Reprod Biol. 2006;124(2):187-192. doi:10.1016/j.ejogrb. 2005.06.012

25. Eze JN, Anozie OB, Lawani OL, Ndukwe EO, Agwu UM, Obuna JA. Evaluation of obstetricians' surgical decision-making in the management of uterine rupture. BMC Pregnancy Childbirth. 2017;17(1):179. doi:10.1186/s12884-017-1367-8

26. Hoffman MS. How to safeguard the ureter and repair surgical injury. OBG Manag. 2008;12(11):16-28.

27. Lescay HA, Jiang J, Tuma F. Anatomy, abdomen and pelvis, ureter. In: StatPearls. Treasure Island (FL): StatPearls Publishing; 2021. Available from: http://www.ncbi.nlm.nih.gov/books/NBK532980/. Accessed August 23, 2021.

28. Esparaz A, Pearl J, Herts B, LeBlanc J, Kapoor B. Iatrogenic urinary tract injuries: etiology, diagnosis, and management. Semin Intervent Radiol. 2015;32(2):195-208. doi:10.1055/s-0035-1549378

29. Yabuki Y. Twenty-first century radical hysterectomy - journey from descriptive to practical anatomy. Gynecol Oncol Rep. 2020;34:100623. doi:10.1016/j.gore.2020.100623
30. Preston JM. Iatrogenic ureteric injury: common medicolegal pitfalls. BJU Int. 2000;86(3):313-317. doi:10.1046/j.1464-410x.2000.00100.x

31. Tantitamit T. Different techniques for evaluation of urologic complication during laparoscopic gynecologic surgery: a review. J South Asian Fed Obstet Gynaecol. 2018;10(4S1):335-339. doi:10.5005/jpjournals-10006-1618

32. Luketic L, Murji A. Options to evaluate ureter patency at cystoscopy in a world without indigo carmine. J Minim Invasive Gynecol. 2016;23(6):878-885. doi:10.1016/j.jmig.2016.06.009

33. Doyle PJ, Duecy E, Wood R. Sodium fluorescein as an alternative to indigo carmine $\mathrm{T}^{\mathrm{TM}}$ during intraoperative cystoscopy. J Minim Invasive Gynecol. 2015;22(3):S65. doi:10.1016/j.jmig.2014.12.147

34. Delbos L, Gareau-Labelle A-K, Langlais E-L, et al. Sodium fluorescein for ureteral jet detection: a Prospective Observational Study. JSLS. 2018;22(3):e2018.00019. doi:10.4293/JSLS.2018.00019

35. Abboudi H, Ahmed K, Royle J, Khan MS, Dasgupta P, N'Dow J. Ureteric injury: a challenging condition to diagnose and manage. Nat Rev Urol. 2013;10(2):108-115. doi:10.1038/nrurol.2012.254

36. Merritt AJ, Crosbie EJ, Charova J, et al. Prophylactic pre-operative bilateral ureteric catheters for major gynecological surgery. Arch Gynecol Obstet. 2013;288(5):1061-1066. doi:10.1007/s00404-0132853-5

37. Patil S, Guru N, Kundargi V, Patil B, Patil N, Ranka K. Posthysterectomy ureteric injuries: presentation and outcome of management. Urol Ann. 2017;9(1):4. doi:10.4103/0974-7796.198838

38. Lawal O, Bello O, Morhason-Bello I, Abdus-salam R, Ojengbede O. Our experience with iatrogenic ureteric injuries among women presenting to university college hospital, Ibadan: a call to action on trigger factors. Obstet Gynecol Int. 2019;2019:1-6. doi:10.1155/2019/6456141

39. Alabousi A, Patlas MN, Menias CO, et al. Multi-modality imaging of the leaking ureter: why does detection of traumatic and iatrogenic ureteral injuries remain a challenge? Emerg Radiol. 2017;24 (4):417-422. doi:10.1007/s10140-017-1507-5

40. Stein R, Rubenwolf P, Ziesel C, Kamal MM, Thüroff JW. Psoas hitch and Boari flap ureteroneocystostomy: Psoas hitch and Boari flap ureteroneocystostomy. BJU Int. 2013;112(1):137-155. doi:10.1111/ bju. 12103

41. Kromann B, Steven K, Hald T, Olsson C. The use of the boari-flap and psoas-bladder hitch technique in the repair of a high ureteric lesion: a case report. Scand J Urol Nephrol. 1986;20(3):233-234. doi:10.3109/00365598609024502

42. Selzman AA, Spirnak JP. Iatrogenic ureteral injuries: a 20-year experience in treating 165 injuries. $J$ Urol. 1996;155(3):878-881. doi:10.1016/S0022-5347(01)66332-8

43. Kunkle DA, Kansas BT, Pathak A, Goldberg AJ, Mydlo JH. Delayed diagnosis of traumatic ureteral injuries. $J$ Urol. 2006;176 (6):2503-2507. doi:10.1016/j.juro.2006.08.003

44. Dowling RA, Corriere JN, Sandler CM. Iatrogenic ureteral injury. J Urol. 1986;135(5):912-915. doi:10.1016/S0022-5347(17)45921-0

45. Nabavizadeh B, Keihani S, Hosseini Sharifi SH, Kajbafzadeh A-M. Insertion of a single double-J stent for bilateral open ureteral reimplantation: introducing a novel technique and assessment of feasibility. Int Urol Nephrol. 2016;48(7):1015-1019. doi:10.1007/ s11255-016-1279-y

\section{Publish your work in this journal}

The International Journal of Women's Health is an international, peerreviewed open-access journal publishing original research, reports, editorials, reviews and commentaries on all aspects of women's healthcare including gynecology, obstetrics, and breast cancer. The manuscript management system is completely online and includes a very quick and fair peer-review system, which is all easy to use. Visit http://www.dovepress.com/testimonials.php to read real quotes from published authors. 